\title{
PENGARUH KONSUMSI BAWANG PUTIH TERHADAP KADAR \\ KOLESTEROL PADA PENDERITA HIPERKOLESTEROLEMIA (Studi di Desa Handil Sohor Kecamatan Mentaya Hilir Selatan Kabupaten Kotawaringin Timur)
}

\author{
Eko Adi Setiawan ${ }^{1}$ Luluk Sulistiyono ${ }^{2}$ Rukmini Syahleman ${ }^{3}$ \\ ${ }^{123}$ STIKes Borneo Cendekia Medika Pangkalan Bun \\ ${ }^{1}$ email : ekosetiawan@gmail.com, ${ }^{2}$ email : luluksulistiyono@gmail.com, ${ }^{3}$ email : \\ rukminisyahleman@gmail.com
}

\begin{abstract}
ABSTRAK
Pendahuluan: Hiperkolesterolemia merupakan salah satu penyebab terjadinya penyakit jantung dan stroke. Hiperkolesterolemia dapat di atasi dengan konsumsi bawang putih. Tujuan dari penelitian ini adalah untuk menganalisa pengaruh konsumsi bawang putih terhadap kadar kolesterol pada penderita hiperkolesterolemia di Desa Handil Sohor. Metode penelitian:Desain penelitian ini menggunakan one group pre tes post tes design pada penderita hiperkolesterolemia di Desa Handil Sohor Tahun 2017 yang berjumlah 32 orang dengan teknik total sampling. Teknik analisis bivariat dengan analisis Wilcoxon sign Rank test dan distribusi frekuensi untuk univariat (kadar kolesterol) . Metode pengumpulan data menggunakan lembar observasi dan alat tes kadar kolesterol untuk variabel hiperkolesterolemia. Hasil penelitian: Kadar kolesterol sebelum konsumsi bawang putih sebagian besar responden mengalami kadar kolesterol kategori sedang dengan jumlah 26 orang (81\%) dengan rata - rata $219 \mathrm{mg} / \mathrm{dl}$. Sedangkan setelah konsumsi bawang putih, responden mengalami kadar kolesterol kategori normal dengan jumlah 20 orang (64\%) dengan rata - rata $204 \mathrm{mg} / \mathrm{dl}$ dengan hasil uji wilcoxon 0,000 menunjukan nilai $\mathrm{p}<0,05$ menggunakan aplikasi SPSS V16.0. Kesimpulan: Berdasarkan hal tersebut maka dapat disimpulkan bahwa terdapat pengaruh yang signifikan antara konsumsi bawang putih terhadap kadar kolesterol pada penderita hiperkolesterolemia. Saran: Memberikan alternatif penanganan kolesterol saat penderita hiperkolesterolemia mengalami kadar kolesterol tinggi selain meminum obat.
\end{abstract}

Kata kunci : bawang putih, kadar kolesterol, hiperkolesterolemia

THE INFLUENCE OF CONSUMPTION OF GARLIC AGAINST CHOLESTEROL LEVELS IN PEOPLE WITH HYPERCHOLESTEROLEMIA (Study in the village of Handil Sohor Subdistric of Mentaya Hilir Selatan Regency of Kotawaringin Timur)

\begin{abstract}
Introduction: Hypercholesterolemia is one of the causes of the occurrence of heart disease and stroke. Hypercholesterolemia can be corrected with the consumption of garlic. The purpose of this study was to analyze the influence of garlic consumption against the cholesterol levels in people with hypercholesterolemia in the village of Handil Sohor. Redeach Mhetod: This research Design using one group pre test post
\end{abstract}


test design on hypercholesterolemia in the village of sufferers Handil Sohor Year 2017 which totaled 32 people with total sampling techniques. Bivariat analysis techniques with analysis of the Wilcoxon signed Rank test and frequency distribution for univariate (cholesterol levels). Data collection method using sheets of observation and tests for cholesterol levels of the variable hypercholesterolemia. Result and discussion: Cholesterol levels before consumption of garlic, most respondents experienced moderate category cholesterol levels with a total of 26 people (81\%) with an average $219 \mathrm{mg} / \mathrm{dl}$. Whereas after consumption of garlic, respondents undergo cholesterol levels normal category with a total of 20 people (64\%) with an average $204 \mathrm{mg} / \mathrm{dl}$ with wilcoxon 0.000 test results show p value < 0.05 using SPSS 16.0 application. Conclusion: Based on this it can be inferred that there was significant influence between the consumption of garlic against cholesterol levels in people with hypercholesterolemia.

Keywords: garlic, levels of cholesterol, hypercholesterolemia

\section{PENDAHULUAN}

Makanan menjadi kebutuhan manusia sehari hari untuk menutrisi tubuh. Makanan mengandung gizi seperti protein, karbohidrat dan juga lemak. Lemak yang di gunakan oleh tubuh sebagai cadangan makan dan cadangan energi akan berguna baik bila jumlahnya dalam batas normal. Namun, jika jumlah lemak dalam tubuh terlalu berlebih maka akan terjadi gangguan - gangguan metabolisme yaitu hiperkolesterolemia. Faktor risiko terjadinya penyakit kardiovaskular seperti jantung koroner (PJK) dan stroke di sebabkan oleh hiperkolesterolemia. Selama ini, hiperkolesterolemia di tangani secara farmakologi seperti mengkonsumsi obat jenis statin, tetapi penggunaan tanaman herbal juga dapat mengatasi kadar kolesterol yang tinggi salah satunya yaitu bawang putih.

Laporan Badan Kesehatan Dunia (WHO), September 2009, menyebutkan bahwa penyakit kardiovaskular merupakan penyebab kematian pertama sampai saat ini. Badan Kesehatan Dunia (WHO) menunjukan $20 \%$ serangan stroke dan
$50 \%$ serangan jantung yang di sebabkan oleh kadar kolesterol tinggi. Di Indonesia, penderita penyakit jantung koroner sebesar 2.650.340 jiwa, penyakit gagal jantung sebesar 229.696 jiwa, dan penderita penyakit stroke sebesar 1.236.825 jiwa yang berkaitan dengan tingginya kejadian hiperkolesterolemia (Kementerian Kesehatan RI, 2013). Kasus ini meningkat pertahunnya sebanyak $28 \%$ dan menyerang usia produktif yaitu usia di bawah 40 tahun (Harian Merdeka, 2013, dikutip dalam Meutia, 2014). Di Provinsi Kalimantan Tengah sebanyak $14.475 \quad$ penderita hiperkolesterolemia risiko terjadinya penyakit jantung dan stroke (KemenKes RI,2013). Data dari DINKES Kabupaten Kotawaringin Timur (2015), terdapat 275 jiwa penderita hiperkolesterolemia di Kecamatan Mentaya Hilir Selatan. Data UPTD Puskesmas Samuda menyebutkan, ada 32 jiwa yang terkena kolesterol tinggi.

Data - data menunjukan bahwa penyakit hiperkolesterolemia yang menjadi faktor resiko terjadinya penyakit kardiovaskular dan stroke menjadi masalah serius yang perlu di 
perhatikan sebagia upaya pencegahan agar tidak berkelanjutan terjadinya penyakit kardiovaskular dan stroke. Bawang putih yang mengandung allicin dan alliin bermanfaat sebagai antikolesterol dan memperkecil gejala dari penyakit jantung dan menyembuhkan tekanan darah tinggi. Pada salah satu studi yang di edarkan dalam The Journal of The Royal Collage of Physicians oleh Silagy CS dan Neil HAW tahun 1994, mengungkapkan bahwa bawang putih merupakan pelopor untuk mengurangi lemak dalam tubuh dan yang terpenting ialah membantu proses penyembuhan dari kolesterol tinggi (Utami \& Mardiana, 2013). Bawang putih di pakai sebagai pengobatan karena di percaya sebagai sumber alliin, yaitu bahan kimia yang mengandung sulfur dari asam amino. Alliin ini membantu meningkat kadar kolesterol HDL atau kolesterol baik sekaligus memperlambat sintesis endogen kolesterol.

Dari masalah yang terurai di atas, peneliti ingin melakukan penelitian yang berjudul "Pengaruh Konsumsi bawang Putih Terhadap Kadar Kolesterol Pada Penderita Hiperkolesterolemia" di Desa Handil Sohor Kecamatan Mentaya Hilir Selatan Kabupaten Kotawaringin Timur Provinsi Kalimantan Tengah.

\section{METODE PENELITIAN}

Desain pada penelitian ini menggunakan preexperimental design.Rancangan penelitian ini menggunakan satu kelompok subjek yang dipilih secara acak. Kelompok perlakuan pengukuran satu kali sebelum dan setelah perlakuan. Efek perlakuan dapat dilihat pada pengukuran sebelum dan sesudah perlakuan. Populasi adalah keseluruhan atau himpunan objek dengan ciri yang sama (Santoso, 2005:46) Populasi dalam penelitian ini yaitu penderita hiperkolesterolemia di Desa Handil Sohor Kecamatan Mentaya Hilir Selatan Kabupaten Kotawaringin Timur sebanyak 32 orang.

Sampel adalah bagian dari populasi yang akan di teliti atau bagian jumlah dari karakteristik yang dimiliki oleh populasi (Hidayat \& Alimun, 2010). Sampel dalam penelitian ini adalah seluruh penderita hiperkolesterolemia di Desa Handil Sohor Kecematan Mentaya Hilir Selatan Kabupaten Kotawaringin Timur yang berjumlah 32 orang dalam satu kelompok. 1 kelompok dilakukan pengukuran nilai kadar kolesterol, yang kemudian dilakukan konsumsi bawang putih, dan di ukur kembali nilai kadar kolesterolnya.

Sampling penelitian adalah suatu proses seleksi sampel yang digunakan dalam penelitian dari populasi yang ada, sehingga jumlah sampel akan mewakili keseluruhan populasi yang ada (Hidayat,2010:81). Peneliti menggunakan teknik Probability sampling dengan metode total sampling.

Instrumen yang digunakan dalam penelitian ini berupa timbangan, lembar observasi dan alat tes kadar kolesterol.

\section{HASIL PENELITIAN}

Data umum

Tabel 1. Distribusi Responden Berdasarkan umur responden di Desa Handil Sohor Juni 2017 


\begin{tabular}{|c|c|c|c|}
\hline No & Umur & Jumlah & $\begin{array}{c}\text { Persentase } \\
(\%)\end{array}$ \\
\hline 1 & $20-29$ & 7 & $22 \%$ \\
\hline 2 & $30-39$ & 10 & $31 \%$ \\
\hline 3 & $>40$ & 15 & $47 \%$ \\
\hline Total & & 32 & $100 \%$ \\
\hline
\end{tabular}

Hampir dari setengahnya responden berusia $>40$ yang berjumlah 15 orang $(47 \%)$.

Tabel 2. Distribusi Responden Berdasarkan Jenis kelamin Responden di Desa Handil Sohor Juni 2017

\begin{tabular}{ccc}
\hline $\begin{array}{c}\text { Jenis } \\
\text { Kelamin }\end{array}$ & Jumlah & $\begin{array}{c}\text { Persentase } \\
(\%)\end{array}$ \\
\hline Laki-laki & 13 & $41 \%$ \\
Perempuan & 19 & $59 \%$ \\
\hline Total & 32 & 100 \\
\hline Data : Data primer 2017 &
\end{tabular}

Sebagian besar dari responden berjenis kelamin perempuan yang berjumlah 19 orang ( $59 \%)$.

Tabel 3. Distribusi Responden Berdasarkan Tingkat Pendidikan di Desa handil Sohor Juni 2017

\begin{tabular}{ccc}
\hline $\begin{array}{c}\text { Tingkat } \\
\text { pendidikan }\end{array}$ & Jumlah & $\begin{array}{c}\text { Persentase } \\
(\%)\end{array}$ \\
\hline Tidak & 0 & $0 \%$ \\
sekolah & & \\
SD & 8 & $25 \%$ \\
SMP & 16 & $50 \%$ \\
SMA & 5 & $16 \%$ \\
Serjana & 3 & $9 \%$ \\
\hline Total & 32 & $100 \%$ \\
\hline Sumber : Data primer 2017 &
\end{tabular}

Setengah responden berpendidikan SMP yang berjumlah 16 orang ( $50 \%$ ).

Tabel 4. Distribusi Responden Berdasarkan tingkat pekerjaan di Desa Handil Sohor Juni 2017

\begin{tabular}{|c|c|c|}
\hline Pekerjaan & Jumlah & $\begin{array}{c}\text { Persentase } \\
(\%)\end{array}$ \\
\hline Tani & 5 & $16 \%$ \\
\hline Swasta & 12 & $37 \%$ \\
\hline PNS & 4 & $12 \%$ \\
\hline Buruh & 3 & $9 \%$ \\
\hline $\begin{array}{c}\text { Ibu rumah } \\
\text { tangga }\end{array}$ & 5 & $16 \%$ \\
\hline $\begin{array}{c}\text { Tidak } \\
\text { bekerja }\end{array}$ & 0 & $0 \%$ \\
\hline Total & 32 & $100 \%$ \\
\hline
\end{tabular}

Hampir dari setengahnya responden bekerja sebagai swasta yang berjumlah 12 orang $(37 \%)$.

Tabel 5. Distribusi responden berdasarkan pendapatan responden di Desa Handil Sohor Juni 2017

\begin{tabular}{ccc}
\hline Pendapatan & Jumlah & $\begin{array}{c}\text { Persentase } \\
(\%)\end{array}$ \\
\hline$<1$ juta & 13 & $41 \%$ \\
$1-3$ juta & 16 & $50 \%$ \\
$>3$ juta & 3 & $9 \%$ \\
\hline Total & 32 & $100 \%$ \\
\hline Sumber : Data primer 2017 &
\end{tabular}

Setengah responden berpendapatan 1 3 juta yang berjumlah 16 orang $(50 \%)$.

Tabel 6. Distribusi Responden Berdasarkan konsumsi makanan berlemak yang sering dikonsumsi

\begin{tabular}{ccc}
\hline $\begin{array}{c}\text { Makanan } \\
\text { berlemak }\end{array}$ & Jumlah & $\begin{array}{c}\text { Persentase } \\
(\%)\end{array}$ \\
\hline Ikan & 5 & $16 \%$ \\
ayam & 7 & $22 \%$ \\
gorengan & 5 & $16 \%$ \\
telur & 15 & $46 \%$ \\
Daging merah & 0 & $0 \%$ \\
\hline Total & 32 & $100 \%$ \\
\hline
\end{tabular}

Sumber : Data primer 2017

Hampir dari setengahnya responden mengkonsumsi makanan berlemak jenis telur yang berjumlah 15 orang $(46 \%)$. 
Tabel 7. Distribusi responden berdasarkan kebiasaan minum di Desa Handil Sohor Juni 2017

\begin{tabular}{|c|c|c|}
\hline $\begin{array}{c}\text { Kebiasaan } \\
\text { minum }\end{array}$ & Jumlah & $\begin{array}{c}\text { Persentase } \\
(\%)\end{array}$ \\
\hline Susu & 12 & $37,5 \%$ \\
\hline Kopi & 14 & $43,8 \%$ \\
\hline Teh & 6 & $18,7 \%$ \\
\hline Alkohol & 0 & $0 \%$ \\
\hline Total & 32 & $100 \%$ \\
\hline
\end{tabular}

Hampir setengah responden memiliki kebiasaan minum kopi yang berjumlah 14 orang $(43,8 \%)$.

Tabel 8. Distribusi responden berdasarkan kejadian obesitas di desa Handil Sohor Juni 2017

\begin{tabular}{|c|c|c|}
\hline Obesitas & Jumlah $\quad \mathrm{P}$ & $\begin{array}{l}\text { Persentase } \\
(\%)\end{array}$ \\
\hline $\mathrm{Ya}$ & 18 & $56 \%$ \\
\hline Tidak & 14 & $44 \%$ \\
\hline Total & 32 & $100 \%$ \\
\hline \multicolumn{3}{|c|}{$\begin{array}{l}\text { Sumber : Data primer } 2017 \\
\text { sebagian besar dari responden } \\
\text { mengalami obestitas berjumlah } 18 \text { or } \\
(56 \%) \text {. }\end{array}$} \\
\hline \multicolumn{3}{|c|}{$\begin{array}{l}\text { Tabel 9. Distribusi responden berdasark } \\
\text { kebiasaan olahraga di Desa Handil Soh } \\
\text { Juni } 2017\end{array}$} \\
\hline $\begin{array}{c}\text { Kebiasan } \\
\text { olahraga }\end{array}$ & Jumlah & $\begin{array}{c}\text { Persentase } \\
(\%)\end{array}$ \\
\hline $\mathrm{Ya}$ & 3 & $9 \%$ \\
\hline Tidak & 29 & $91 \%$ \\
\hline Total & 32 & $100 \%$ \\
\hline
\end{tabular}

Hampir seluruhnya responden tidak pernah melakukan olahraga berjumlah 29 orang $(91 \%)$.

Tabel 10. Distribusi responden berdasarkan kebiasaan merokok di Desa Handil Sohor Juni 2017

\begin{tabular}{ccc}
\hline $\begin{array}{c}\text { Kebiasaan } \\
\text { Merokok }\end{array}$ & Jumlah & $\begin{array}{c}\text { Persentase } \\
(\%)\end{array}$ \\
\hline Ya & 8 & $25 \%$ \\
Tidak & 24 & $75 \%$ \\
\hline Total & 32 & $100 \%$ \\
\hline Sumber : Data primer 2017 &
\end{tabular}

Sebagian kecil dari responden memiliki kebiasaan merokok berjumlah 8 orang $(25 \%)$.

Data khusus

Tabel 11. Distribusi Responden Berdasarkan Kadar Kolesterol sebelum konsumsi bawang putih di Desa Handil Sohor Juni Tahun 2017

\begin{tabular}{ccc}
\hline $\begin{array}{c}\text { Kadar } \\
\text { Kolesterol }\end{array}$ & Jumlah & $\begin{array}{c}\text { Persentase } \\
(\%)\end{array}$ \\
\hline Normal & 0 & $0 \%$ \\
sedang & 26 & $81 \%$ \\
Tinggi & 6 & $19 \%$ \\
\hline Total & 32 & $100 \%$ \\
\hline Sumber : Data primer 2017 \\
diketahui hampir seluruhnya dari \\
responden mengalami kadar kolesterol \\
sedang yaitu sebanyak 27 orang $(81 \%)$.
\end{tabular}

Tabel 12. Distribusi Responden Berdasarkan Kadar Kolesterol sesudah konsumsi bawang putih di Desa Handil Sohor Juni 2017

\begin{tabular}{lcc}
\hline $\begin{array}{c}\text { Kadar } \\
\text { Kolesterol }\end{array}$ & Jumlah & $\begin{array}{c}\text { Persentase } \\
(\%)\end{array}$ \\
\hline Normal & 20 & $64,5 \%$ \\
Sedang & 12 & $37,5 \%$ \\
Tinggi & 0 & $0 \%$ \\
\hline Total & 32 & $100 \%$ \\
\hline Sumber : Data primer & 2017 \\
sebagian besar & dari & responden \\
mengalami kadar kolesterol normal yaitu \\
sebanyak 20 orang (64,5\%). \\
Tabel 13. Distribusi kadar kolesterol \\
karena pengaruh konsumsi bawang putih \\
terhadap kadar kolesterol di Desa Handil \\
Sohor Juni 2017
\end{tabular}


Hampir seluruhnya responden sebelum diberikan konsumsi bawang putih mengalami kadar kolesterol sedang sebanyak 26 orang (81\%) dan setelah diberikan konsumsi bawang putih selama 21 hari sebagian besar dari responden mengalami kadar kolesterol normal sebanyak 20 orang $(64,5 \%)$.

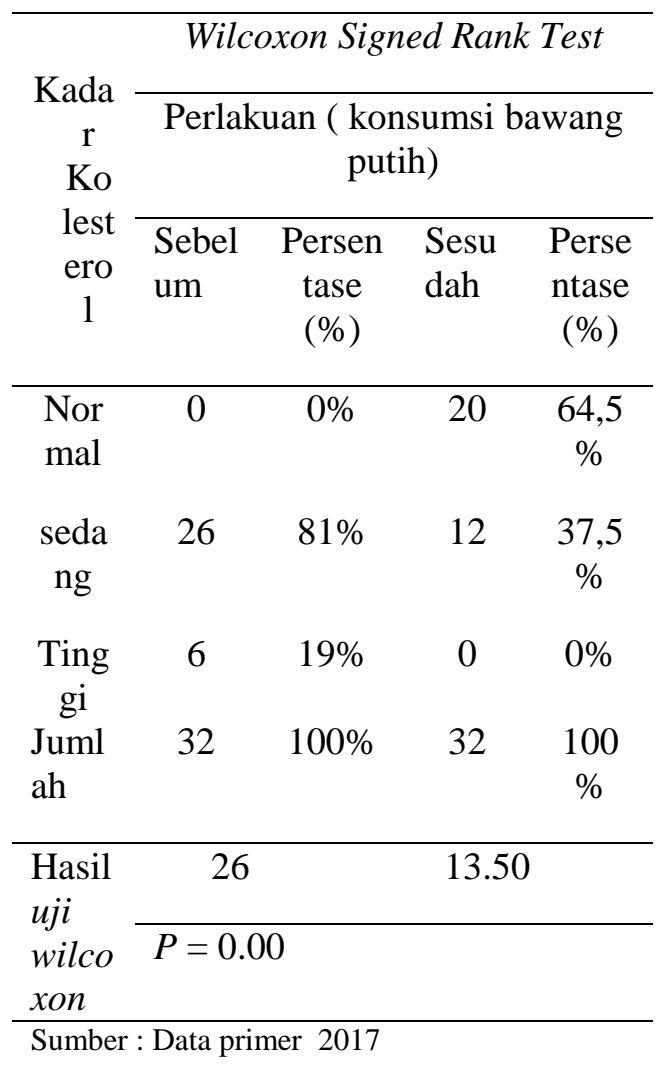

Hasil pengujian statistik dengan menggunakan uji Wilcoxon Signed Rank Tes dengan tingkat kemaknaan $\alpha$ $<0,05$ didapat hasil $\mathrm{p}$ value $=0,00$ karena nilai sig.(2-tailed) $0,00<0,05$ maka Ho ditolak dan $\mathrm{H} 1$ diterima, maka ada pengaruh konsumsi bawang putih terhadap kadar kolesterol pada penderita hiperkolesterolemia.

\section{PEMBAHASAN}

Kadar kolesterol sebelum diberikan konsumsi bawang putih
Tabel 11 diketahui hampir seluruhnya dari responden mengalami kadar kolesterol sedang sebelum diberikan bawang putih yaitu sebanyak 27 orang $(81 \%)$.

Menurut peneliti, meningkatnya kadar kolesterol disebabkan oleh beberapa faktor. Faktor tersebut antara lain Umur, jenis kelamin, kebiasaan makanan berlemak, kebiasaan minum, kejadian obesitas, kebiasaan olahraga dan kebiasaan merokok.

Semakin bertambahnya usia manusia, semakin meningkat pula kadar kolesterolnya. Selain itu, jenis kelamin juga mempengaruhi kadar kolesterol. Wanita sebelum menopause mempunyai kadar kolesterol yang lebih rendah di bandingkan pria dengan usia yang sama. Namun setelah menopause, kadar koletserol wanita cenderung meningkat (Rusilanti, 2014, 22).

Menurut Guyton (2007) yang menyatakan bahwa asupan diet tinggi lemak jenuh turut meningkatkan kadar kolesterol plasma dengan peningkatan sebanyak $15 \%$ - 25\%. Hal ini karena terjadi deposit lemak di hati yang kemudian menyebabkan meningktanya unsur asetil-koA di hati untuk memproduksi kolesterol.

Makanan yang dikonsumsi akan mengalami proses metabolisme dan menghasilkan adenosin triphosphate (ATP). ATP merupakan energi untuk melakukan aktivitas fisik. Pembentukan ATP disesuaikan dengan kebutuhan, sehingga tidak semua makanan yang dikonsumsi akan diubah langsung menjadi ATP melainkan ada yang disimpan dalam bentuk kolesterol. Semakin banyak aktivitas fisik yang dilakukan maka semakin banyak kebutuhan ATP dan akan menyebabkan sedikitnya pembentukan 
kolesterol total dan kolesterol LowDensity Lipoprotein (LDL) serta peningkatan Hight-Density Lipoprotein (HDL) (Zuhroiyyah S.F et al, 2017).

Menurut Veena et al (2014) nikotin yang merupakan komponen utama dari rokok dapat meningkatkan sekresi dari katakolamin sehingga meningkatkan lipolisis. Hal ini menyebabkan meningkatnya kadar trigliserida, kolesterol, dan VLDL.

Kadar kolesterol sesudah konsumsi bawang putih

Berdasarkan tabel. 12 diketahui sebagian besar dari responden mengalami kadar kolesterol normal yaitu sebanyak 20 orang $(64,5 \%)$.

Menurut peneliti, kandungan kimia dalam bawang putih terutama allicin yang menghambat enzim HMG-KoA dalam pembentukan kolesterol dalam hati.

Senyawa Allicin bersaing dengan substrat enzim yaitu HMG-KoA, terdapat kemiripan struktur antara senyawa Allicin (inhibitor) dengan HMG-KoA (substrat), sehingga di duga senyawa Allicin ini merupakan inhibitor kompetitif dari enzim HMGKoAreduktase (Brajawikalpa \& Kautama, 2016).

Pengaruh konsumsi bawang putih terhadap kadar kolesterol pada penderita hiperkolesterolemia

Berdasarkan tabel 13 menunjukkan secara diskriptif terlihat terdapat pengaruh konsumsi bawang putih terhadap kadar kolesterol pada penderita hiperkolesterolemia. analisa menggunakan uji Wilcoxon signed rank test, didapatkan $P=0.000$, maka $\mathrm{p}<$ 0.05 .
Menurut peneliti, berdasarkan hasil uji Wilcoxon signed rank test, terdapat pengaruh yang signifikan pada kadar kolesterol sebelum dan sesudah diberikan konsumsi bawang putih

Senyawa Allicin bersaing dengan substrat enzim yaitu HMG-KoA, terdapat kemiripan struktur antara senyawa Allicin (inhibitor) dengan HMG-KoA (substrat), sehingga di duga senyawa Allicin ini merupakan inhibitor kompetitif dari enzim HMGKoA reduktase (Brajawikalpa \& Kautama, 2016).

\section{KESIMPULAN DAN SARAN}

Kesimpulan

1. Sebelum diberikan konsumsi bawang putih kadar kolesterol pada penderita hiperkolesterolemia sebagian besar menderita hiperkolesterolemia sedang

2. Setelah diberikan konsumsi bawang putih kadar kolesterol pada penderita hiperkolesterolemia lebih dari setengah memiliki kadar kolesterol yang normal

3. Ada pengaruh konsumsi bawang putih terhadap kadar kolesterol pada penderita hiperkolesterolemia

Saran

1. Bagi responden

Memberikan alternatif penanganan kolesterol saat mereka mengalami kadar kolesterol tinggi selain meminum obat.

2. Bagi Unit Puskesmas

Sebagai masukan bagi Puskesmas untuk penanganan kadar kolesterol tinggi mengenai manfaat bawang putih sebagai alternatif lain selain obat untuk mengatasi kadar kolesterol tinggi. 
3. Bagi peneliti selanjutnya

Agar melakukan penelitian tentang faktor lain yang berhubungan dengan konsumsi bawang putih terutama faktor yang mempengaruhi konsumsi bawang putih tentunya dengan dosis yang berbeda maupun jangka waktu pemberian yang berbeda.

\section{DAFTAR PUSTAKA}

Adi, L. T. (2008). Tanaman obat

Mengatasi Penyakit Jantung, Hipertensi, Kolesterol, dan Stroke. Jakara: Agromedia.

Arikunto, \& Suharsimi. (2006). Prosedur Penelitian. Jakarta: Renika Cipta.

Aziz, A., Alimul, \& Hidayat. (2010). Metode Penelitian Kesehatan Paradigma Kuantitatif. Surabaya: Health books.

Bangun. (2003). Terapi Jus \& Ramuan Tradisonal Untuk Kolesterol. Jakarta: Agromedia Pustaka.

Budiarto, E. (2002). Biostatika Untuk Kedokteran dan Kesehatan Masyarakat. Jakarta: EGC.

Brajawikalpa, R. S., \& Kautama, M. G. (2016, 5 4). Pengaruh Pemberian Ekstrak Etanol Bawang Putih Terhadap Kadar Kolesterol Total, LDL Dan HDL Pada Tikus Putih Hiperkolesterol. Retrieved Mei 2, 2017, from TUNAS MEDIKA JURNAL
KEDOKTERAN

DAN KESEHATAN:

http://jurnal.unswagati.ac.id/i ndex.php/tumed/article/view/ 288

Guyton, A. C., \& Hall, J. (2008). Buku Ajar Fisiologi Kedokteran. Jakarta: ECG.

Handayani, A. (2006). 812 Resep Untuk Mengobati 236 Penyakit. Jakarta: Penebar Swadaya.

M. U. (2014, Februari). Retrieved Mei 1, 2017, from Document Repository Universitas Andalas:

http://repo.unand.ac.id/id/epr int/404

Notoatmodjo, S. (2014). Metodologi Penelitian Kesehatan. Jakarta: Renika Cipta.

Nursalam. (2003). Konsep dan Penerapan Metodologi Penelitian Ilmu Keperawatan. Jakarta: Salemba Medika.

Nursalam. (2013). Konsep dan Metode Penelitian Ilmu Keperawatan. jakarta: Salemba Medika.

Priskilla, M. (2008). Pengaruh pemberian Ekstrak Bawang Putih (allium sativium, Linn.) Terhadap Penurunan Rasio Antara Kolesterol Total Dengan Kolesterol HDL Pada Tikus Putih (Rattus Norvegicus) Yang 
Hiperkolesterolemik.

Universitas Sebelas Maret, $7-20$.

Rusilanti. (2014). Kolesterol Tinggi

Bukan Untuk Di Takuti.

FMedia.

Santoso, G. S. (2005). Metodologi penelitian Kualitatif dan Kuantitatif. Jakarta: Prestasi Pustaka.

Sugiyono. (2006). Metode penelitian Administrasi. Bandung: Alfabeta.

Utami, P., \& Mardiana, L. (2013). Umbi Ajaib Tumpas Penyakit. Jakarta: Penebar Swadaya.

Wijayakusuma, M. H. (2008). Ramuan Herbal Penurun Kolesterol. Jakarta: Pustaka Bunda.

Wikipedia. (2016). Retrieved Mei 2, 2017, from Kolesterol: https://id.wikipedia.org/wiki/ Kolesterol 